University of Nebraska - Lincoln

DigitalCommons@University of Nebraska - Lincoln

Faculty Publications, Department of Psychology

Psychology, Department of

June 2000

\title{
Anticipating Adulthood: Expected Timing of Work and Family Transitions Among Rural youth
}

\author{
Lisa J. Crockett \\ University of Nebraska-Lincoln, ecrockett1@unl.edu \\ C. Raymond Bingham \\ University of Michigan
}

Follow this and additional works at: https://digitalcommons.unl.edu/psychfacpub

Part of the Psychiatry and Psychology Commons

Crockett, Lisa J. and Bingham, C. Raymond, "Anticipating Adulthood: Expected Timing of Work and Family Transitions Among Rural youth" (2000). Faculty Publications, Department of Psychology. 230.

https://digitalcommons.unl.edu/psychfacpub/230

This Article is brought to you for free and open access by the Psychology, Department of at DigitalCommons@University of Nebraska - Lincoln. It has been accepted for inclusion in Faculty Publications, Department of Psychology by an authorized administrator of DigitalCommons@University of Nebraska - Lincoln. 
JOURNAL OF RESEARCH ON ADOLESCENCE, 10(2), 151-172

Copyright $\bigcirc 2000$, Lawrence Erlbaum Associates, Inc.

\title{
Anticipating Adulthood: Expected Timing of Work and Family Transitions Among Rural Youth
}

\author{
Lisa J. Crockett \\ Department of Psychology \\ University of Nebraska-Lincoln \\ C. Raymond Bingham \\ Department of Psychiatry \\ University of Michigan
}

\begin{abstract}
This study examined family and individual processes influencing the future expectancies of adolescents $(N=345)$ from an economically stressed rural community. The anticipated timing and sequencing of key role transitions (school completion, job entry, marriage, and parenthood) were examined for each gender. In addition, factors contributing to individual differences in expected timing were examined, and gender differences in predictors were tested. Results indicated that rural adolescents' expectancies about adult role transitions diverged somewhat from societal norms with respect to timing. Family background and relationships, adolescents' attitudes and behaviors, and educational aspirations all contributed to individual differences in expected timing, with somewhat different factors being salient for boys and girls. These findings provide clues to the psychological processes linking adolescent experiences to the construction of the adult life course.
\end{abstract}

The process by which individuals construct their lives is a core issue for developmental researchers (e.g., Clausen, 1995; Elder, 1998). Individuals shape their development by selecting environments and by interacting with others in habitual ways (Caspi, Bem, \& Elder, 1989; Lerner, 1982). At

Requests for reprints should be sent to Lisa J. Crockett, Department of Psychology, 319 Burnett Haü, University of Nebrasḱa-Lincoin, Lincoin, NE 68588-0308. E-mail: ecrockett1@unl.edu 
the same time, their actions are influenced by demands and opportunities afforded by the social context (Hogan \& Astone, 1986). Central to this ongoing negotiation between person and context are the cognitions individuals bring to their interactions with the environment-their goals, hopes, and expectations. These cognitions help guide the choices that ultimately shape deveiopmental trajectories (Cantor, 1990; Nurmi, 1993). This study focuses on one set of influential cognitions-adolescents' expectancies regarding the timing of their transitions to adult work and family roles. These expectancies reflect adolescents' general plans for the next stage of development (Hogan, 1985) and predict their actual behavior (Hogan, 1986).

Although a number of studies have examined the ages at which work and family role transitions typically occur (e.g., Hogan, 1981; Marini, 1987), relatively little research has focused on the expectations young people bring to these events. In this study, we examine rural adolescents' projections about when they will experience key role transitions and compare them to societal norms, in an effort to locate adolescents' expectancies within an ecological context. We also identify personal and family factors contributing to individual differences in expected timing among rural youth.

\section{SOCIAL NORMS AND PERCEPTIONS OF THE LIFE COURSE}

Individuals' expectations and plans for the future are thought to be structured by institutional patterns (Hogan \& Astone, 1986) and by shared assumptions about the typical life course (Kohli \& Meyer, 1986; Neugarten, 1979). According to this perspective, young people acquire shared perceptions of the adult life course through cumulative exposure to social institutions (Greene, 1990). Over time, normative patterns are internalized and influence a youth's personal expectations for the future. For the transition to adulthood, the normative sequence of events involves school completion, followed by entry into the labor market, marriage, and parenthood (Greene, 1990). Insofar as social norms influence adolescents' perceptions of the future, we would expect their projections to mirror the normative sequence.

Prior research on adolescents' expectations is consistent with the normative hypothesis. Hogan (1982) examined young adolescents' expectancies about the timing of school completion, job entry, marriage, and parenthood, and found that, on average, they followed the predicted sequence. Moreover, in two cross-sectional studies, Greene (1990; Greene, Wheatley, \& Aldava, 1992) found that older adolescents' expectations regarding the nature of future life events showed greater agreement than did 
those of younger adolescents. The greater convergence of expectations among older adolescents is consistent with a gradual acquisition of a shared vision of adult life.

Although societal norms provide a general road map of the future life course, local conditions may modify adolescents' expectancies. Ianni (1989) argued that the community plays a powerful role in shaping adolescents' perceptions of the future. Consistent with this perspective, Burton, Allison, and Obeidallah (1995) found that African American adolescents from poor urban neighborhoods envision a foreshortened life course, compared to mainstream youth. Other ecological settings may also affect adolescents' expectancies, but this possibility remains largely unexplored.

\section{FUTURE EXPECTANCIES OF RURAL YOUTH}

Rural adolescents provide a unique vantage point for examining the role of the ecological context in shaping young people's expectations for the future. During this century, rural communities have experienced economic decline due to global market trends and a reorganization of farming and extractive industries (Freudenberg, 1992). As a result, many rural youth face shrinking occupational opportunities in their home communities (e.g., Hobbs, 1994) and develop their vision of the future under conditions of economic uncertainty. The limited economic opportunities are thought to influence rural adolescents' aspirations for the future (Wilson \& Peterson, 1988). Consistent with this perspective, nonmetropolitan youth report lower educational and occupational aspirations than do metropolitan youth (Haller \& Virkler, 1993). Moreover, rural adolescents anticipate earlier entry into adult work and family roles, relative to more advantaged suburban youth (Stemmler, Bingham, Crockett, Petersen, \& Meyer, 1991). Such findings suggest that economic conditions in rural areas may lead adolescents to anticipate an early transition to adulthood.

\section{SOURCES OF VARIABILITY IN FUTURE EXPECTANCIES}

Although as a group rural adolescents may anticipate a relatively early transition to adult roles, there may also be substantial within-group variability in expectancies. Prior studies have documented considerable diversity in adolescents' expected timing of role transitions (Greene, 1990; Greene et al., 1992; Hogan, 1985), but such studies have rarely sought to identify the sources of this diversity. Based on a national sample of youths, 
Hogan reported differences in expectancies associated with race, gender, social class, parental expectations, and adolescents' aspirations. Similarly, Stemmler et al. (1991) found individual differences in expected timing associated with gender and parental educational attainment among rural youth. In this study, we sought to identify additional factors influencing the future expectancies of rural youth. In light of previous research on expected and actual timing of adult role transitions (e.g., Hogan, 1985; Marini, 1985) and a comprehensive review of the literature on rural youth (Crockett, Shanahan, \& Jackson-Newsom, 2000), four main sources of variability were examined. These included family background (socioeconomic status, family structure, family relationships), gender role attitudes, prior behavior (school performance, problem behaviors), and educational aspirations.

\section{Family Background and Relationships}

Low parental educational attainment has been linked to lower educational aspirations in youth (e.g., Sewell \& Hauser, 1980) and to expectations of earlier transitions to adult work and family roles (Hogan, 1985; Stemmler et al., 1991). Similarly, nonintact family structure has been linked to high school dropout (Zimiles \& Lee, 1991) and lower educational attainment (Blau \& Duncan, 1967). Thus, lower parent education and nonintact family structure were expected to foster expectations of earlier role transitions related to schooling and work.

The quality of family relationships may also influence adolescents' expectancies concerning role transitions. Among rural youth, close family ties may foster early role transitions by anchoring young people to communities with few high level jobs and few incentives for postsecondary education (e.g., Donaldson, 1986). Alternatively, poor family relationships may create an incentive for early role transitions; one study found that rural girls with poor parent-child relationships expected to marry and begin childbearing at younger ages than girls with better parent-child relationships (Crouter, Carson, Vicary, \& Butler, 1988).

\section{Adolescent Aspirations, Attitudes, and Behaviors}

A second source of within-group differences in expected timing includes personal attitudes and behaviors. In particular, plans for extended education (e.g., college) are likely to be associated with expectations of delayed employment, marriage, and parenthood because schooling tends to pre- 
cede entry into adult roles (Hogan, 1978; Marini, 1985). Similarly, because school performance affects opportunities for postsecondary education, high marks in school may foster expectations of later transitions to adult roles. Gender role attitudes may also influence future expectancies. Because traditional gender roles emphasize a gender-based division of labor, with men being responsible for economic support of the family and women focusing on the roles of wife and mother (e.g., Eccles, 1994), adherence to such attitudes may promote expectations of eariy job entry among men and early school completion, marriage, and parenthood among women.

Finally, participation in problem behaviors may affect adolescents' future expectancies. According to Jessor (1984), adolescents engage in substance use, sexual behavior, and other norm-breaking behaviors to assert their claim to adult status. If so, involvement in these behaviors could indicate a proneness toward early role transitions. Consistent with this notion, Newcomb and Bentler (1988) found that adolescent substance use was associated with earlier school completion, labor force participation, marriage, and parenthood. However, the extent to which adolescents expected these early role transitions was not examined.

\section{GENDER DIFFERENCES IN PREDICTORS OF EXPECTED TIMING}

Gender differences in the potency of some predictors of future expectancies seem likely, given the different social roles of men and women. Educational variables may be stronger predictors for girls than boys, because the role conflicts between achievement-related roles (e.g., student, worker) and family roles are greater for women than for men (Eccles, 1994; Hogan, 1985). Women also tend to marry earlier than men, reducing the interval between school completion and marriage and thereby increasing the potential for role overlap (Marini, 1985). Thus, women must orchestrate their role transitions carefully so that schooling does not compete with family roles. The importance of educational factors in the timing of role transitions may be especially marked in rural populations where women tend to marry early (McLaughlin, Lichter, \& Johnston, 1993).

Gender role attitudes may also exert a greater impact on girls' expectations than on boys. Employment opportunities in many rural areas are severely limited for women (McLaughlin et al., 1993; Wilson. Peterson, \& Wilson, 1993) and consist largely of low-pay, low-prestige jobs. Thus, girls with nontraditional career aspirations have to pursue their goals elsewhere, probably through advanced education. Such girls should anticipate later role transitions than their more traditional peers. Finally, 
parental influences may have gender-differential effects. Hogan (1985) reported that parents' educational aspirations for their children and their expectations about the timing of childbearing were more strongly associated with girls' projected timing of marriage and childbearing than with the projections of boys.

In summary, this study examined the projected timing and sequencing of adult role transitions in a sample of rural adolescents and sought to identify individual and family predictors of expected timing. Previous studies (e.g., Greene, 1990; Greene et al., 1992; Hogan, 1985) have provided general models of the development of future expectancies but have not linked these expectancies to local ecological conditions. This study takes the next step of placing adolescents' future expectations in context, specifically that of a disadvantaged rural community in the latter half of the 1980 s. We hypothesized that rural adolescents' expectations would reflect an accelerated transition to adulthood. We further anticipated that both family factors and individual achievements, attitudes, and aspirations would predict individual differences in expected timing among rural youth. Finally, we expected that some factors would have differential effects for boys and girls.

\section{METHOD}

\section{Sample}

Data came from a larger longitudinal study of rural adolescent development initiated in 1985. A cohort-sequential longitudinal design was employed (e.g., Baltes, 1968) in which three grade cohorts of adolescents (those initially in Grades 7, 8, and 9 of a single rural school district) were surveyed annually through 12 th grade. Data were collected each fall by project personnel during regular school hours, with boys and girls being surveyed separately. Toensure confidentiality, teachers and school administrators were excluded from the survey process, no names were used on questionnaires, and students were monitored during the survey.

All students in the designated cohorts were included in the sample except those whose parents refused consent and those who were absent on the day of testing. Over $90 \%$ of the target population participated in any given year. Students classified as learning disabled or special education were excluded from data analysis.

To maximize the sample size for each grade level, data from the three cohorts were pooled by grade. The few students who repeated a grade in high school were retained in their original cohort to maintain the integrity 
of the design. Tests for cohort effects in the pooled data were all nonsignificant, indicating no bias due to cohort differences.

These analyses were based on data from 10th, 11th, and 12th grades. Only students with data from at least two of the three designated grade levels were included. Because the focus was on expectations, students who reported that they had already made one or more of the transitions were excluded from analysis ( 18 girls and 21 boys), along with one adolescent who did not expect to marry or have children. In addition, four adolescents who reported improbable expectations (e.g., girls who planned to initiate childbearing after age 40 ) were excluded. The final sample included 345 European Americans (175 girls and 170 boys) from lower- to middle-class families.

Community. The participating school district served a geographically contained rural area in the Allegheny range of the eastern United States. The district includes a number of small boroughs and townships located approximately $3 \mathrm{hr}$ from any large urban area. Community residents are almost exclusively White, lower to middle class, and of European descent. Census data from 1980 indicated that the primary occupational categories in the school district were laborers and technical-clerical. At that time, $69 \%$ of the adults had a high school education or less, the median family income was $\$ 14,500$, and there was a $12 \%$ poverty rate.

Traditionally, coal mining was the primary source of employment, supplemented by a few small manufacturing plants (a cigar factory, a few garment and textile factories) and some light industry. In the 1980s, the area began to experience severe economic stress, with major employment losses in every sector. The mining operation slowed and shut down, and the cigar factory closed. By 1987, unemployment in the region was reported at $19.6 \%$.

\section{Measures}

These analyses included family demographic variables (parents' educational attainment and family structure) measured at 10th grade, adolescent attitudes and experiences measured at 11th grade, and expected timing of role transitions assessed at 12 th grade. The 12 th grade was selected for the outcome measures because adolescents' expectations should be most accurate at that point. The other time points were chosen to be temporally prior to 12 th grade. 
Parental educational attainment (10th grade). Adolescents were asked to report how far each parent had gone in school, and the scores of the two parents were averaged. Adolescents in stepfamilies were allowed to report the educational attainment of the stepparent instead of the absent biological parent; for adolescents in single-parent families, only the educational attainment of the resident parent was used.

Family structure (10th grade). Adolescents identified the adults they lived with most of the time. Possible responses included: both natural parents, natural mother and stepfather, natural father and stepmother, mother only, father only, legal guardian, grandparents, and foster parents. For these analyses, responses were dichotomized to reflect either intact families (two biological parents) or nonintact families (any other configuration); in most cases, the number of adolescents in specific nonintact configurations was too small to permit reliable analysis for boys and girls separately.

Family relationships (11th grade). The perceived quality of family relationships was assessed by the Family Relations subscale of the Self-Image Questionnaire for Young Adolescents (Petersen, Schulenberg, Ebata, Offer, \& Jarcho, 1984). Reliability and validity were established (Petersen et al., 1984). The family relationships subscale consists of 17 items (e.g., "I can count on my parents most of the time") coded on a 6-point Likert-type scale ranging from 1 (very strongly agree) to 6 (very strongly disagree). Items were averaged to create a total score, with higher scores indicating better family relationships. Alpha coefficients ranged from .82 to .91 across the annual surveys.

Gender role attitudes (11th grade). Gender role attitudes were measured with the Attitudes Towards Women Scale for Adolescents (Galambos, Petersen, \& Gitelson, 1985). A typical item is, "Girls are as smart as boys." Reliability and validity of the scale were well documented (Galambos et al., 1985). Items were coded on a 4-point scale ranging from 1 (strongly agree) to 4 (strongly disagree) and then averaged, with a high score reflecting more egalitarian attitudes. Alpha coefficienis ranged from .72 to .75 in the annual surveys.

School performance (11th grade). Adolescents were asked to report their typical school grades on a scale ranging from 1 (mostly Fs) to 8 (mostly $A s$ ). Prior research shows a high correlation between self-reported and actual grades (Baird, 1976; Crockett, Schulenberg, \& Petersen, 1987).

Problem behavior (11th grade). Problem behavior was assessed using the Primary Prevention Awareness, Attitudes, and Usage Scale (PPAAUS; 
Swisher, Shute, \& Bibeau, 1984). The PPAAUS assesses the frequency of specific behaviors on a scale ranging from 1 (never) to 5 (almost every day). Three scales were used: misconduct (average frequency of 11 antisocial behaviors ranging from cheating to vandalism and stealing), substance use (average frequency of getting drunk and getting high on drugs; $r=.51$ ), and sexual activity (average frequency of necking, petting, and sexual intercourse). Alpha coefficients for misconduct ranged from .75 to .81 in the annual surveys; the alpha for sexual activity at 11 th grade was .85 .

Educational expectations (11th grade). Adolescents were asked how far they planned to go in school. Answers ranged from 1 (some high school) to 6 (professional degree).

Expected timing of adult transitions (12th grade). Adolescents reported the ages at which they expected to finish their full-time schooling, get their first "real" job, get married, and have their first child.

\section{Data Preparation}

To maintain sample sizes across analyses, missing data were estimated using a procedure initially suggested by Petersen for imputing missing values in longitudinal data (Bingham, Stemmler, Petersen, \& Graber, 1999; cf. Bingham \& Crockett, 1996). The procedure estimates missing values based on the group mean of the variable in question and the individual's average deviation from the mean on that variable at other times of measurement. Missing values were estimated separately for boys and girls. To check for bias created by the estimation procedure, the sample covariance structure before and after imputation was compared, using a LISREL stacked two-group (estimated vs. observed covariance structure) design in which all parameter estimates were constrained to be invariant across the two groups (Jöreskog \& Sörbom, 1989). The goodness-of-fit index exceeded .99, indicating that the estimated data set accurately represented the original data.

\section{RESULTS}

\section{Expected Timing and Sequencing of Role Transitions}

Mean expected ages of rule transitions were computed for each gender. For girls, $M=20.64, S D=2.24$ for school completion; $M=20.50, S D=2.33$ for first job; $M=22.75, S D=2.68$ for marriage; and $M=24.44, S D=2.97$ for 
parenthood. For boys, $M=21.20, S D=2.83$ for school completion; $M=$ $20.99, S D=2.78$ for first job; $M=24.25, S D=3.45$ for marriage; and $M=$ 25.20, $S D=3.42$ for parenthood. Girls anticipated significantly earlier transitions than boys in three instances: school completion, $F(1,343)=$ $4.19, p<.05$; marriage, $F(1,343)=20.29, p<.001$; and parenthood, $F(1,343)$ $=4.83, p<.05$.

\section{Predictors of Expected Timing}

As a preliminary step, the correlations between predictors and outcome variables were examined for each gender (Table 1). The educational plans predictor was significantly associated with expected ages of all transitions for both genders. However, school marks and parent educational attainment were consistently related to the timing variables for girls only. Furthermore, the associations between problem behavior (substance use and misconduct) and outcomes differed for the two genders. When significant, they were positive for girls and negative for boys.

\section{Multiple Regressions}

Two regression models were tested for each of the four outcome variables. The first model contained the 10th-grade family background variables (parents' education and family structure) along with the 11th-grade measures of adolescent attitudes and experiences (family relationships, gender

TABLE 1

Correlations Between Predictors and Expected Age at Four Transitions, by Gender

\begin{tabular}{|c|c|c|c|c|c|c|c|c|}
\hline \multirow[b]{2}{*}{ Predictor } & \multicolumn{2}{|c|}{ Finish School } & \multicolumn{2}{|c|}{ First Job } & \multicolumn{2}{|c|}{ Marry } & \multicolumn{2}{|c|}{ First Child } \\
\hline & Girls & Boys & Girls & Boys & Girls & Boys & Girls & Boys \\
\hline Parent education & $.39^{* * *}$ & .10 & $.36^{* * *}$ & .07 & $.23^{* *}$ & .02 & $.23^{* *}$ & .10 \\
\hline Nonintact family & -.00 & $-.22^{* *}$ & .02 & -.12 & .02 & .09 & .06 & .08 \\
\hline $\begin{array}{l}\text { Gender role } \\
\text { attitudes }\end{array}$ & .10 & .11 & $.16^{*}$ & .12 & $.19^{*}$ & $.17^{*}$ & $.17^{*}$ & $.23^{* *}$ \\
\hline $\begin{array}{l}\text { Family } \\
\text { relationships }\end{array}$ & .02 & $.21^{* *}$ & .04 & .12 & -.08 & -.08 & $-.16^{\star}$ & .04 \\
\hline Marks & $.39 * * *$ & $.19^{*}$ & $.35^{* * *}$ & $.33^{* * *}$ & $.22^{* *}$ & .07 & $.17^{*}$ & .14 \\
\hline Misconduct & .06 & $-.21^{* *}$ & .01 & -.12 & $.16^{*}$ & .06 & $.25^{* *}$ & -.12 \\
\hline Substance use & -.05 & $-.25^{* *}$ & .09 & $-.23^{* *}$ & $.16^{*}$ & .02 & .14 & $-.15^{*}$ \\
\hline Sexual behavior & $-.20^{* *}$ & -.14 & $-.21^{* *}$ & -.09 & -.10 & -.09 & -.07 & -.14 \\
\hline Educational plans & $.55^{* * *}$ & $.28^{* * *}$ & $.49^{* *}$ & $.37 * * *$ & $.36^{* * *}$ & $.17^{*}$ & $.30^{* * *}$ & $.15^{*}$ \\
\hline
\end{tabular}

${ }^{*} p<.05 .{ }^{* *} p<.01 .{ }^{* * *} p<.001$. 
TABLE 2

Regressiuns Predictirig the Expected Age of Nônfamilial Transitions, by Gender

\begin{tabular}{|c|c|c|c|c|c|c|c|c|}
\hline \multirow[b]{3}{*}{ Predictor } & \multicolumn{4}{|c|}{ Finish School } & \multicolumn{4}{|c|}{ First Job } \\
\hline & \multicolumn{2}{|c|}{ Girls } & \multicolumn{2}{|c|}{ Boys } & \multicolumn{2}{|c|}{ Girls } & \multicolumn{2}{|c|}{ Boys } \\
\hline & $B$ & $\beta$ & $B$ & $\beta$ & $B$ & $\beta$ & $B$ & $\beta$ \\
\hline Parent education & .47 & $.19^{* 4}$ & .06 & .02 & .44 & $.18^{*}$ & -.15 & -.05 \\
\hline Nonintact family & .15 & .03 & -.95 & -.15 & .28 & .05 & -.29 & -.05 \\
\hline $\begin{array}{l}\text { Family } \\
\text { relationships }\end{array}$ & -.38 & $-13^{*}$ & .31 & .08 & -.32 & -.11 & -.10 & -.03 \\
\hline $\begin{array}{l}\text { Gender role } \\
\text { attitudes }\end{array}$ & -.23 & -.04 & .13 & .02 & .19 & .03 & .13 & .02 \\
\hline Marks & .50 & $.24^{* * *}$ & .05 & .02 & .41 & $.19^{*}$ & .51 & $.21^{*}$ \\
\hline Substance use & .10 & .03 & -.32 & -.10 & -.04 & -.01 & -.49 & -.15 \\
\hline Misconduct & .53 & .10 & -.46 & -.07 & .39 & .07 & .35 & .06 \\
\hline Sexual behavior & -.26 & -.12 & .04 & .02 & $-.2 \overline{8}$ & -.12 & .04 & .02 \\
\hline Educational plans & .66 & $.40^{* * * *}$ & .38 & $.18^{*}$ & .58 & $.33^{* * * *}$ & .51 & $.24^{* *}$ \\
\hline$R^{2}$ & 41 & & .15 & & .32 & & .19 & \\
\hline
\end{tabular}

${ }^{*} p<.05 .{ }^{* *} p<.01 .{ }^{* * *} p<.001 .{ }^{* * * *} p<0.0001$.

role attitudes, school performance, and problem behaviors). In the second model, 11th-grade educational plans was added. For brevity, only the final models are presented.

School completion. Table 2 shows the results for nonfamilial role transitions (school completion and job entry) for girls and boys separately. Among girls, higher parental education, poorer family relationships, better marks, and higher educational plans significantly predicted later school completion. Initial effects of sexual behavior and misconduct became nonsignificant when educational plans was included in the prediction model; thus, these effects may operate through educational plans. Among boys, educational plans was the only significant predictor in the final regression model. ${ }^{1}$ Boys with higher aspirations anticipated later school completion.

Job eniry. Among giris, parental education, school marks, and educational plans significantly and positively predicted expected age of job entry (Table 2). An initial effect of sexual behavior decreased to nonsignificance when educational plans was entered into the regression model, suggesting

\footnotetext{
${ }^{1}$ The effect of noninitact fantily structure was sigruficant unail plans were included in the regression equation. Although this suggests that nonintact family structure operates indirectly through educational plans, formal criteria for mediation were not met (cf. Baron \& Kenny, 1986).
} 
that sexual behavior operated indirectly, through educational plans. Among boys, school marks and educational plans were significant predictors. Higher marks and higher aspirations both delayed the expected timing of labor force entry.

Marriage. Results for familial role transitions are reported in Table 3. For girls, school marks, substance use, and educational plans significantly predicted expected age of marriage. The effects of marks and educational plans were in the expected direction, with better school performance and higher aspirations delaying girls' expected age of job entry. The positive effect for substance use indicated that more frequent substance use delayed the projected timing of marriage. Initial effects of gender role attitudes and parents' education declined to nonsignificance when educational plans was included in the model; thus, these factors may operate through girls' educational plans. Among boys, only sexual behavior had a significant effect in the final model, with more sexual activity predicting an earlier expected age of marriage. ${ }^{2}$

Parenthood. For girls, family relationships, school marks, misconduct, and educational plans predicted the expected age of parenthood (Table 3). High marks and educational plans operated as predicted, delaying girls' projected age of childbearing. Adolescent misconduct delayed the anticipated timing of childbearing, whereas good family relationships tended to accelerate it. The initial effects of parental education and gender role attitudes were lost when educational plans was included in the regression model, so these effects may operate through girls' educational plans. Among boys, gender role attitude was the only significant predictor of expected timing of parenthood; more egalitarian attitudes were associated with later projected onset of parenthood.

\section{Gender Differences in Predictors}

Gender differences in the influence of individual predictors on adolescents' expectancies were tested formally via interaction terms. Interactions between gender and each predictor variable were examined in separate regression models conducted with the pooled sample of boys and girls. Each model included gender, the predictor, and the interaction term. Seven of

\footnotetext{
${ }^{2}$ The initial effect of gender role attitudes disappeared when educational plans was included in the equation. Additional analyses revealed evidence of collinearity among educational plans, gender role attitudes, and sexual behavior. Thus, the loss of the gender role attitudes effect probably reflects multicollinearity.
} 
TABLE 3

Regressions Predicting the Expected Age of Familial Transitions, by Gender

\begin{tabular}{|c|c|c|c|c|c|c|c|c|}
\hline \multirow[b]{3}{*}{ Predictor } & \multicolumn{4}{|c|}{ Marry } & \multicolumn{4}{|c|}{ First Child } \\
\hline & \multicolumn{2}{|c|}{ Girls } & \multicolumn{2}{|c|}{ Boys } & \multicolumn{2}{|c|}{ Girls } & \multicolumn{2}{|c|}{ Boys } \\
\hline & $B$ & $\beta$ & $B$ & $\beta$ & $B$ & $\beta$ & $B$ & $\beta$ \\
\hline Parent education & 0.25 & .09 & 0.03 & .01 & 0.38 & .12 & 0.33 & .10 \\
\hline Nonintact family & 0.22 & .04 & 0.53 & .07 & 0.42 & .06 & 0.61 & .08 \\
\hline $\begin{array}{l}\text { Family } \\
\text { relationships }\end{array}$ & -0.47 & -.14 & -0.59 & -.12 & -0.71 & $-.19^{*}$ & -0.36 & -.08 \\
\hline $\begin{array}{l}\text { Gender role } \\
\text { attitudes }\end{array}$ & 0.72 & .11 & 1.17 & .15 & 0.89 & .12 & 1.47 & $.19^{*}$ \\
\hline Marks & 0.47 & $.19^{*}$ & 0.21 & .07 & 0.52 & $.19^{*}$ & 0.36 & .12 \\
\hline Substance use & 0.85 & $.21^{*}$ & 0.49 & .12 & 0.24 & .06 & -0.10 & -.02 \\
\hline Misconduct & 0.55 & .08 & 0.87 & .11 & 1.81 & $.25^{* *}$ & -0.23 & -.03 \\
\hline Sexual behavior & -0.38 & -.15 & -0.58 & $-.19^{*}$ & -0.33 & -.12 & -0.30 & -.10 \\
\hline Educational plans & 0.49 & $.25^{* *}$ & 0.41 & .16 & 0.37 & $.17 *$ & 0.03 & .01 \\
\hline$R^{2}$ & 0.25 & & 0.10 & & 0.25 & & 0.10 & \\
\hline
\end{tabular}

${ }^{*} p<.05 .{ }^{* *} p<.01$

the possible 36 interactions were significant in these tests; these are discussed in turn.

For the anticipated age of school completion, four interactions with gender were significant: those for parent education, family structure, family relationships, and misconduct. The Gender $\times$ Parental Education interaction indicated that the positive bivariate relation between parental education and expected age at school completion (see Table 1 ) was significantly stronger for girls than boys, $\beta=-.47, p<.05$. In contrast, a positive effect of family relationships, $\beta=.72, p<.05$, and a negative effect of nonintact family structure, $\beta=-19, p<.05$, pertained mainly to boys. (Both correlations were near zero for girls.) Finally, a significant interaction between gender and misconduct, $\beta=-.64, p<.01$, indicated that the relation between misconduct and timing of school completion differed for the two genders, being significant and negative for boys but nonsignificant and positive for girls (see Table1).

The interaction between parent education and gender was significant for age atjobentry, $\beta=-.51, p<.05$. The positive effect of parents' education was stronger for girls (it was nonsignificant for boys). Finally, two interactions were significant for expected age of parenthood: Gender $\times$ Substance Use, $\beta=-.44, p<.01$, and Gender $\times$ Misconduct, $\beta=-.84, p<.001$. The interaction with misconduct reflected a significant, positive association with expected age of parenthood among girls but a negative, nonsignificant association among boys. The interaction with substance use reflected a 
nonsignificant, positive association for girls and a significant, negative association for boys. To summarize, the significant interactions with gender indicated that parental educational attainment figured more strongly for girls than boys, other family factors were more potent for boys, and deviant behavior (substance use and misconduct) had divergent effects for the two genders.

\section{DISCUSSION}

This study provides important insights into the anticipated life course of rural boys and girls. The projected ages of adult role transitions indicate that both genders envisioned a sequence of transitions in which school completion and job entry would come first (at about the same age), followed by marriage and finally parenthood. Data on the actual timing of role transitions in the United States in the late 1980 s provide a basis of comparison with national patterns. These data (cited in Greene, 1990) indicate that the median age for starting one's career in the late 1980s was 22; for marriage, it was 23.3 for women and 26.5 for men; and for parenthond, it was 23.6 (women only) ${ }^{3}$ Based on these data, the expected sequencing of work and family transitions in this sample was largely consistent with the pattern of actual role transitions experienced nationally. Moreover, in line with actual transitions in contemporary and earlier cohorts (Greene, 1990; Marini, 1978, 1987), girls anticipated younger ages of school completion, marriage, and parenthood than did boys, but a similar age of job entry. This consistency supports the operation of either a shared vision of the life course (Greene, 1990), institutional arrangements that delineate a normative pathway to adulthood, or both (Hogan \& Astone, 1986).

Nonetheless, an important divergence from national patterns was noted in the timing of role transitions. As predicted, the sample anticipated a relatively early transition to work (at approximately age 21 for both genders) and marriage (age 22.8 for women and age 24.3 for men). Contrary to prediction, however, the mean expected age of parenthood reported by the rural girls was later than the actual median age of parenthood among women. This discrepancy may be attributable to the fact that very early childbearers were largely excluded from the analyses. Had actual age of parenthood been assessed for the full sample of girls, the average may have more closely mirrored the national median.

\footnotetext{
${ }^{3}$ The national figures included two ages for school completion: age 17 for high school graduation and age 22 for college graduation. Thus, no direct comparison was possible.
} 
A comparison with the ages reported by suburban adolescents in other research (Stemmler et al., 1991) provides further evidence of an accelerated timetable among rural youth. In that study, the average expected ages reported by 12 th-grade girls were approximately 23 for school completion and starting one's first full-time job, 26 for marriage, and 29 for parenthood. For 12th-grade boys, the reported ages were 24 for school completion and first job, 27 for marriage, and 29.5 for parenthood. Compared with these suburban adolescents, this sample anticipated substantially earlier entry into all four roles. This pattern is consistent with the notion that disadvantaged rural youth anticipate an accelerated transition to adulthood.

The evidence of an accelerated timetable among rural youth suggests that local conditions may influence adolescents' vision of their future life course. For example, the economic decline in the rural community under study and in other rural communities may constrain adolescents' perceptions of their future educational and vocational options (e.g., Wilson \& Peterson, 1988). Limited options and economic hardship, in turn, are linked to accelerated transitions to adult roles (Burton et al., 1995; Elder, 1998).

\section{Family and Individual Factors Influencing Expectancies}

Within the rural sample, both familial and individual factors predicted adolescents' expectations for the future. Educational plans figured prominently in adolescents' projections, as reported in prior research (Hogan, 1985). In fact, educational aspirations emerged as a key factor organizing adolescents' perceptions of the future, with higher educational aspirations being associated with anticipated delays in all four role transitions. Better school performance was also correlated with later projected timing of role transitions, especially among girls. As an indicator of academic competence, higher marks may increase educational aspirations, thereby fostering expectations of later school completion and job entry. However, marks often had an effect independent of educational plans, suggesting that they index other factors, such as a realistic appraisal of how long schooling will actually take or a preference for an extended adolescence.

Among girls, there was also evidence that some factors operated indirectly, through educational plans. Effects of sexual behavior on expected ages of school completion and job entry became nonsignificant when educational plans was included in the regression models. Also, effects of gender role attitudes and parental education on timing of family transitions dropped out once girls' educational plans were con- 
trolled. These results suggest a possible mediating role of educational plans for girls, an issue that merits attention in future studies. More broadly, these results underscore the importance of educational plans in girls' future expectancies.

Parental education, gender role attitudes, and sexual behavior showed effects in the hypothesized direction, with parental education and nontraditional attitudes delaying expected timing and sexual involvement accelerating it. However, these effects varied by gender.

\section{Gender Differences in Predictors of Expectancies}

The most striking outcome of this study was the differential impact of several factors for girls versus boys. One important difference was the comparatively greater impact of educational factors for girls' future plans. Educational aspirations predicted girls' expectancies regarding all four transitions, but among boys, this factor was consistently related only to timing of school completion and labor market entry. Marks, too, had a more consistent effect for girls than for boys. Although interactions between these factors and gender were not significant, the pattern of results is in accord with previous research showing that educational aspirations are more central to girls' future plans than to boys' future plans (Hogan, 1985). They are also in keeping with earlier demographic data indicating that educational attainment has a greater impact on women's timing of familial role transitions than on men's (e.g., Marini, 1985). The impact of educational variables may be especially strong among rural girls, who, on average, marry earlier than their metropolitan peers (McLaughlin et al., 1993). In future studies, it would be useful to compare the impact of high educational aspirations among rural, urban, and suburban girls to determine whether this influence is significantly greater for rural girls.

Parents' educational attainment also had stronger effects for girls than for boys, as indicated by two significant interactions. Among girls, higher parental education was significantly associated with later expected ages of all four role transitions; among boys, none of these associations was significant. Higher parental education may index greater educational resources and support for girls, which would facilitate an extended education. In this study, direct effects of parental education were found for girls' expected timing of school completion and job entry. Possibly, more educated parents encourage longer schooling and later job entry, granting girls more time to acquire an education and "find themselves." In contrast, the effects of parental education on projected timing of marriage and childbearing appeared to operate through girls' educational plans. Educated parents 
foster higher educational aspirations (Sewell \& Hauser, 1980), which may lead girls to anticipate delayed family transitions.

The absence of a relation between parental education and boys' expectancies is surprising, because effects for both genders have been reported in some previous research (e.g., Hogan, 1985). Hogan employed a national sample and did not examine patterns separately for rural and metropoli$\tan$ youth; thus, the pattern may be specific to rural populations. If replicated, the pattern suggests that parental education has different implications for rural boys and girls. For both genders, higher parental education may be associated with increased expectations for postsecondary schooling. Among girls, this leads to plans for later marriage and parenthood. Among boys, however, the age of marriage is typically late enough so that additional schooling does not affect the timing of family transitions (Marini, 1985).

These results point to gender differences in the impact of several other variables not examined in prior research. Nonintact family structure was correlated with plans for accelerated school completion among boys but not girls, a difference that was significant. Boys in nonintact families may feel a need to complete schooling quickly, perhaps in response to family economic stress, but data on family income would be needed to examine this issue. Perceived quality of family relationships also had a significantly different effect on boys' and girls' plans for school completion. For boys, good family relationships were correlated with plans for later school completion, suggesting that parental social support enables boys to extend their time in school (i.e., to take their time). For girls, however, good fanily relationships were associated with expectations of earlier school completion, once educational plans were controlled. Thus, good family relationships appeared to increase girls' optimism about their ability to complete their desired level of schooling quickly, suggesting a facilitative role of parental support. Possibly, good family relationships encourage girls to complete their desired level of schooling quickly to move into adult family roles. The finding that good family relationships predicted earlier childbearing plans among girls is consistent with this interpretation.

Problem behaviors (substance use and misconduct) operated differently for girls and boys, as confirmed by three significant interactions. Where significant correlations were found, they were negative for boys (i.e., linked to earlier projected ages) but positive for girls (i.e., linked to later projected ages). The boys' pattern is in accordance with the notions of transition-proneness and precocious development set forth by Jessor (1984) and Newcomb and Bentler (1988), in which problem behavior promotes early role transitions. In contrast, the girls' pattern is consistent with the developmental delay hypothesis posited by Baumrind 
and Moselle (1985), in which substance use is associated with psychosocial immaturity and delayed role transitions. The divergent effects for the two genders suggest that problem behaviors have different meanings for boys and girls, perhaps reflecting more serious problems among girls.

It is also interesting that the regression models explained more variation in the expected timing of role transitions among girls than among boys. Indeed, in several cases, the percentage of variance accounted for among girls was more than twice that accounted for among boys. Clearly, the models were more effective in predicting girls' expectations. One possible explanation is that girls of high school age have given more thought to their future role transitions compared to their male peers, and girls have a more elaborated vision of what they will be doing and how various aspects of their lives may affect each other. Because girls' friendships involve more self-disclosure than those of boys (e.g., Camarena, Sarigiani, \& Petersen, 1990), girls may have had more opportunity to discuss these future scenarios with peers and to develop a clear view of their futures. Boys' attention may be focused on more immediate concerns, and their view of the future may be more vague and less clearly conceived. If so, we would expect greater reliability and consistency in girls' reports and greater ability to predict those reports.

Taken together, the results point to the possible influence of societal norms, community characteristics, family variables, and individual factors on adolescents' expectations about their future lives. Thus, the typical focus on family and individual predictors of future expectancies may need to be broadened to include community-level and societal variables (e.g., Greene, 1990; Ianni, 1989). Several caveats should be noted, however. First, the results are based on a sample of youth from a single, economically stressed rural community, so the effects of rural traditions cannot be disentangled from those of ongoing economic stress. Research with diverse communities is needed to address this issue. Furthermore, if these findings reflect unique rural adaptations, they may not generalize to youth from nonrural communities. The uniqueness of rural youth is a topic of debate, with some investigators pointing to the similarities between rural and urban youth (e.g., Conger, Patterson, \& Ge, 1995) and others emphasizing the unique adaptations of particular rural populations (e.g., Elder \& Conger, 1996). Finally, the causal processes may be more complicated than those discussed here. For example, expected timing of role transitions could affect adolescents' effort and performance in school, as well as the reverse. Although our use of longitudinal data allows us to specify the temporal ordering of variables in regression models, we cannot rule out alternative causal sequences. 
Despite these limitations, the findings contribute to the sparse literature on processes influencing adolescents' perceptions of the future life course. They suggest that adolescents are sensitive to normative societal patterns and local conditions reflecting economic and occupational opportunities. Beyond this, rural adolescents' expectancies are influenced by family background, personal attitudes and behaviors, and educational aspirations. Somewhat different factors shape the expectancies of rural boys and girls, with parental education and educational aspirations figuring morc prominently for girls than for boys. These findings shed light on the processes influencing rural youths ${ }^{\prime}$ perceptions of the future and provide clues to the ways in which adolescents construct their future lives.

\section{ACKNOWLEDGMENTS}

This research was supported by Grant APR 000933-01 and Contract 282-90-0047 awarded to Judith R. Vicary from the Office of Adolescent Pregnancy Programs, and by grants to Lisa J. Crockett from the College of Health and Human Development and the Center for the Study of Child and Adolescent Development at Pennsylvania State University. A faculty research fellowship from the Research Council of the University of Nebraska-Lincoln supported completion of the manuscript. We gratefully acknowledge the contributions of the participating schools and adolescents, as well as the efforts of the entire staff of the Rural Adolescent Development Study. We are indebted to Michael Shanahan for his valuable comments on an earlier version of this manuscript.

\section{REFERENCES}

Baird, L. L. (1976). Using self-reports to predict student performance (Research Monograph No. 7). Now York: College Entrance Examination Board.

Baltes, P. B. (1968). Longitudinal and cross-sectional sequences in the study of age and generation effects. Human Development, 11, 145-171.

Baron, R. M., \& Kenny, D. A. (1986). The moderator-mediator variable distinction in social psychological research: Conceptual, strategic, and statistical considerations. Journal of Personality and Social Psychology, 51,1173-1182.

Baumrind, D., \& Moselle, K. A. (1985). A developmental perspective on adolescent drug use. Advances in Alcohol and Substance Ulse, 5, 41-6\%.

Bingham, C. R., \& Crockett, L. J. (1996). Longitudinal adjustment patterns of boys and girls experiencing early, middle, and late sexual intercourse. Developmental Psychology, 32, $647-658$.

Bingham, C. R., Stemmler, M., Petersen, A. C., \& Graber, J. A. (1998). Imputing missing data values in repeated measures within-subjects designs. Methods in Psychological Research [http:/ / www.pabst-publishers.de], 3(2), 131-155.

Blau, P., \& Duncan, O. D. (1967). The American occupational structure. New York: Wiley. 
Burton, L. M., Allison, K.W., \& Obeidallah, D. (1995). Social context and adolescence: Perspectives on development among inner-city African-American teens. In L. J. Crocketit \& $\dot{A}$. C. Crouter (Eds.), Pathways through adolescence: Individual development in relation to social contexts (pp. 119-138). Mahwah, NJ: Lawrence Erlbaum Associates, Inc.

Camarena, P. M., Sarigiani, P. A., \& Petersen, A. C. (1990). Gender-specific pathways to intimacy in early adolescence. Journal of Youth and Adolescence, 19(1), 19-32.

Cantor, N. (1990). From thought to behavior: "Having" and "doing" in the study of personality and cognition. American Psychologist, 45, 735-750.

Caspi, A., Bem, D. J., \& Elder, G. H., Jr. (1989). Continuities and consequences of interactional styles across the life course. Journal of Personality, 57, 375-404.

Clausen, J. A. (1995). Gender, contexts, and turning points in adults' lives. In P. Moen, G. H. Elder, Jr., \& K. Luscher (Eds.), Examining lives in context: Perspectives on the ecology of human development (pp. 365-389). Washington, DC: American Psychological Association.

Conger, R. D., Patterson, G., \& Ge, X. (1995). It takes two to replicate: A mediational model for the impact of parents' stress on adolescent adjustment. Child Development, $66,80-97$.

Crockett, L. J, Schulenberg, J. E., \& Petersen, A.C. (1987). Congruence between objective and self-report data in a sample of young adolescents. Journal of Adolescent Research, 2, 383-392.

Crockett, L. J., Shanahan, M. J., \& Jackson-Newsom, J. (2000). Rural youth: Ecological and life course perspectives. In R. Montemayor (Ed.), Advances in Adolescent Development: Vol. 10. Adolescent diversity in ethnic, economic, and cultural contexts (pp. 43-74). I housand Uaks, CA: Sage.

Crouter, A. C., Carson, J. H., Vicary, J. R., \& Butler, J. (1988). Parent-child closeness as an influence on the projected life course of rural adolescent girls. Journal of Early Adolescence, 8 , 345-355.

Donaldson, G. A. (1986). Do you need to leave home to grow up? The rural adolescents' dilemma. Research on Rural Education, 3(3), 121-125.

Eccles, J. (1994). Understanding women's educational and occupational choices: Applying the Eccles et al. model of achievement-related choices. Psychology of Women Quarterly, 18 , $585-609$.

Elder, G. H., Jr. (1998). The life course and human development. In W. Damon (Series Ed.) \& R. M. Lemer (Vol. Ed.), Handbook of child psychology: Vol. 1. Theoretical models of human development (5th ed., pp. 939-1028). New York: Wiley.

Elder, G. H., Jr., \& Conger, R. (with King, V., Mekos, D., Russcll, S., \& Shanahan, M.). (1906). New worlds, new lives: Rural generations at century's end. Chapel Hill: University of North Carolina at Chapel Hill, Social Change Project.

Freudenberg, W. R. (1992). Addictive economies: Extractive industries and vulnerable localities in a changing world economy. Rural Sociology, 57, 305-332.

Galambos, N. L., Petersen, A. C., \& Gitelson, I. B. (1985). The Attitudes Toward Women Scale for Adolescents (AWSA): A study of reliability and validity. Sex Roles, 13, 343-356.

Greene, A. L. (1990). Great expectations: Constructions of the life course during adolescence. Joumal of Youth and Adolescence, 19(4), 289-306.

Greene, A. L., Wheatley, S.M., \& Aldava, J.F. (1992). Stages on life's way: Adolescents' implicit theories of the life course. Journal of Adolescent Research, 7, 364-381.

Haller, E. J., \& Virkler, S. J. (1993). Another look at rural-nonrural differences in students' educational aspirations. Journal of Research in Rural Education, 9(3), 170-178.

Hobbs, D. (1994). Demographic trends in nonmetropolitan America. Joumal of Research in Rural Education, 10(3), 149-160. 
Hogan, D. P. (1978). The effects of demographic factors, family background, and early job achievement on âge at mantiağe. Demography, $15,139-160$.

Hogan, D. P. (1981). Transitions and social change: The early lives of American men. New York: Academic.

Hogan, D. P. (1982). Adolescent expectations about the sequencing of early life transitions. Unpublished manuscript.

Hogan, D. P. (1985). Parental influences on the timing of early life transitions. Current Perspectives on Aging and the Life Cycle, 1, 1-59.

Hogan, D. P. (1986). Maternal influences on the timing of early life transitions. Current Perspectives on Aging and the Life Cycle, 2, 147-165.

Hogan, D. P., \& Astone, N. M. (1986). The transition to adulthood. Annual Review of Sociology, $12,109-130$.

Ianni, F. A. (1989). The search for structure: $A$ report on American youth today. New York: Free Press.

Jessor, R. (1984). Adolescent development and behavioral health. In J. D. Matarazzo, S. M. Weiss, J. A. Herd, N. E. Miller, \& S. M. Weiss(Eds.), Behavioral health: A handbook of health enhancement and disease prevention (pp. 69-90). New York: Wiley.

Jöreskog, K. G., \& Sörbom, D. (1989). LISREL 7: A guide to the program and applications [Software manual, 2nd ed.]. Chicago: SPSS Inc.

Kohli, M., \& Meyer, J. W. (1986). Social structure and social construction of life stages. Human Development, 29, 145-149.

Lemer, R. M. (1982). Chiduren and adolescents as producers of their own development. Developmental Review, 2,342-370.

Marini, M. M. (1978). The transition to adulthood: Sex differences in educational attainment and age at marriage. American Sociological Review, 43, 483-507.

Marini, M. M. (1985). Determinants of the timing of adult role entry. Social Science Research, 14, 309-350.

Marini, M. M. (1987). Measuring the process of role change during the transition to adulthood. Social Science Research, 16, 1-38.

McLaughlin, D. K., Lichter, D. T., \& Johnston, G. M. (1993). Some women marry early: Transitions to first marriage in metropolitan and nonmetropolitan areas. Journal of Marriage and the Family, 55, 827-838.

Neugarten, B. L. (1979). Time, age and the life cycle. American Journal of Psychiatry, 136, 887-894.

Newcomb, M. D. \& Bentler, P. M. (1988). Consequences of adolescent drug use: Impact on the lives of young adults. Newbury Park, CA: Sage.

Nurmi, J. E. (1993). Adolescent development in age-graded context: The role of personal beliefs, goals, and strategies in the tackling of developmental tasks and standards. International Journal of Behavioral Development, 16, 169-189.

Petersen, A. C., Schulenberg, J. E., Ebata, A., Offer, D., \& Jarcho, H. (1984). A Self-Image Questionnaire for Young Adolescents (SIQYA): Reliability and validity studies. Joumal of Youth and Adolescence, 13(2), 93-111.

Sewell, W.H., \& Hauser, R. M. (1980). The Wisconsin longitudinal study of social and psychological factors in aspirations and achievements. Research in Sociology of Education and Socialization, 1, 59-99.

Stemmler, M., Bingham, C. R., Crockett, L. J., Petersen, A. C., \& Meyer, A. (1991, July). Normative expectations in different developmental contexts. Paper presented at the meeting of the International Society for the Study of Behavioral Development, Minneapolis, $\mathrm{MN}$. 
Swisher, J. D., Shute, R. E., \& Bibeau, D. (1984). Assessing drug and alcohol abuse: An instrument for planning and evaluation. Measurement and Eraluation in Counseling and Development, 12, 91-97.

Wilson, S. M., \& Peterson, G. W. (1988). Life satisfaction among young adults from rural families. Family Relations, 37, 84-91.

Wilson, S. M., Peterson, G. W., \& Wilson, P. (1993). The process of educational and occupational attainment of adolescent females from low-income, rural families. Journal of Marriage and the Family, 55, 158-195.

Zimiles, H., \& Lee, V. E. (1991). Adolescent family structure and educational progress. Dexelopmental Psychology, 27, 314-320. 